\title{
Letrozole and Fulvestrant Combination in Second Line or More for Estrogen Receptor Positive Metastatic Breast Cancer; Efficacy and Predictive Factors of Response
}

\author{
M.S. Copur ${ }^{1 *}$, A.M. Obermiller ${ }^{1}$ R. Ramaekers', M. Bolton ${ }^{1}$, B. Luebbe ${ }^{2}$, S. Schneider ${ }^{2}$, J. Goering ${ }^{2}$, W. Marsh ${ }^{3}$, D. Novinski ${ }^{3}$, K. Mleczko ${ }^{4}$, S. \\ Woodward ${ }^{4}$, B. Keenportz ${ }^{4}$, S. Frankforter ${ }^{4}$ and Max Norvell ${ }^{1}$
}

${ }^{1}$ Saint Francis Cancer Treatment Center, Grand Island, NE

${ }^{2}$ Surgery Group of Grand Island, Grand Island, NE

${ }^{3}$ Saint Francis Medical Center, Radiology Department, Grand Island, NE

${ }^{4}$ Saint Francis Medical Center, Pathology Department, Grand Island, NE

\begin{abstract}
Background: Preclinical data show that complete estrogen blockade by both down regulating estrogen receptor and inhibiting estrogen synthesis, has greater effect on tumor growth than either treatment alone. Combination of an aromatase inhibitor and fulvestrant may be an optimal second line therapy by preventing activation of growth factor pathways and possible cross talk with ER. One clinical study has shown no benefit of adding anastrozole to fulvestrant at first relapse. No clinical data on combination letrozole and fulvestrant in the second line or more metastatic beast cancer setting is available.
\end{abstract}

Methods: Estrogen receptor $(\mathrm{ER})$ positive, progesterone receptor $(\mathrm{PgR})$ positive or negative metastatic breast cancer patients with prior chemo and/or non-aromatase inhibitor (non-Al) endocrine therapy were treated with letrozole and fulvestrant. Patients with complete response(CR) partial response(PR), or stable disease(SD) were considered to have clinical benefit (CR+PR+SD). The predictive effects of age, number of prior regimens, ER/PgR status, histology, sites of metastatic disease were examined using Chi-square test.

Results: Thirty-two patients received oral letrozole $2.5 \mathrm{mg}$ daily plus fulvestrant $250 \mathrm{mg}$ intramuscular injection monthly. Mean age was 70 (range: 35-92), median number of prior treatments was 2 (range2-6). 25 pts had ER+/ $\mathrm{PgR}+, 7$ pts had ER+/PgR- tumors. Twenty-five patients had prior non-Al endocrine therapy. Eight patients had lobular histology. Overall clinical benefit rate was $71 \%$ (3 CR, 7 PR, and $13 \mathrm{SD}$ ). Mean duration of the clinical benefit was 15 months (range 2-38). Nine patients progressed under therapy. Age more than 65 versus younger ( $89 \%$ vs $46 \%, P=0.007)$, prior treatments less than 4 versus more $(87 \%$ vs $25 \%, P=0.0007)$ and $E R+/ P g R+$ versus $\mathrm{ER}+/ \mathrm{PgR}-(84 \%$ versus $42 \%, \mathrm{P}<0.05)$ were predictive of clinical benefit; lobular histology, bone versus visceral metastases and prior endocrine therapy did not have affect clinical benefit rate $(P>0.05)$.

Conclusions: In previously treated metastatic breast cancer patients, combination of letrozole and fulvestrant can be effective with a mean clinical benefit duration of 15 months. Older age, less than four prior lines of therapy, and expression of both $\mathrm{ER} / \mathrm{PgR}$ are predictive of clinical benefit while lobular histology, site of metastatic disease and prior non-Al endocrine therapy are not. Letrozole and fulvestrant combination can be a reasonable option in selected group of previously treated metastatic breast cancer patients and should be further evaluated in larger studies utilizing recently approved high dose $(500 \mathrm{mg})$ fulvestrant schedule.

\section{Introduction}

Endocrine therapy of breast cancer is a good example of the earliest targeted therapy for hormone receptor positive breast cancer. Historically it has included two main strategies in reducing the effects of estrogen on tumor growth; one by blocking estrogen from binding to its receptor and the other by inhibiting estrogen synthesis with aromatase inhibitors in the postmenopausal setting. The antiestrogen tamoxifen has been used since 1970s. However, tamoxifen exhibits both estrogen agonist and antagonist effects depending on its target tissue [1]. The search for a pure antiestrogen has led to the development of estrogen receptor down regulating agent fulvestrant. Fulvestrant binds to the estrogen receptor competitively, and in contrast to tamoxifen, it inhibits, and degrades the receptor [2-4]. Fulvestrant has demonstrated clinical efficacy with good tolerability when used as first, second, or third-line therapy in postmenopausal women with hormone receptor positive metastatic breast cancer [4-7]. Blocking both estrogen receptor and estrogen synthesis with a combination of pure antiestrogen and an aromatase inhibitor might have an additive effect. Preclinical data have shown greater inhibitory effect on tumor growth when fulvestrant and an aromatase inhibitor combined, as opposed to either treatment used alone on ovariectomized athymic mice bearing tumors of estrogen receptor positive human breast cancer cells [8-9]. Based on the theoretical advantage of utilizing fulvestrant in a lower estrogen

*Corresponding author: M.S. Copur, MD, FACP, Saint Francis Cancer Treatmen Center, 2116 W Faidley Ave, Grand Island NE 68803, USA, Tel: 308398 5450; Fax: 308398 5351; E-mail: mcopur@sfmc-gi.org

Received November 16, 2011; Accepted December 06, 2011; Published December 08, 2011

Citation: Copur MS, Obermiller AM, Ramaekers R, Bolton M, Luebbe B, et al. (2011) Letrozole and Fulvestrant Combination in Second Line or More for Estrogen Receptor Positive Metastatic Breast Cancer; Efficacy and Predictive Factors of Response. J Cancer Sci Ther S2. doi:10.4172/1948-5956.S2-003

Copyright: ( 2011 Copur MS, et al. This is an open-access article distributed unde the terms of the Creative Commons Attribution License, which permits unrestricted use, distribution, and reproduction in any medium, provided the original author and source are credited. 
Citation: Copur MS, Obermiller AM, Ramaekers R, Bolton M, Luebbe B, et al. (2011) Letrozole and Fulvestrant Combination in Second Line or More for Estrogen Receptor Positive Metastatic Breast Cancer; Efficacy and Predictive Factors of Response. J Cancer Sci Ther S2. doi:10.4172/1948-5956.S2-003

Page 2 of 4

environment, clinical studies evaluating the combination of aromatase inhibitors with fulvestrant have been under way. SWOG-S0226 is comparing anastrozole plus fulvestrant to anastrozole alone as first-line therapy in postmenopausal women. The SoFEA study has randomized hormone receptor positive locally advanced/metastatic postmenopausal breast cancer patients to fulvestrant, exemestane, or fulvestrant plus anastrozole, after failure of a non-steroidal aromatase inhibitor [10]. Results of these trials are eagerly awaited. So far, only one large clinical trial has reported results showing no benefit of adding anastrozole to fulvestrant at first relapse [11]. No clinical data on the effects of combination of letrozole plus fulvestrant in the second line or more have been reported in metastatic breast cancer patients. Here we present our data on the combination of letrozole plus fulvestrant in previously treated post menopausal hormone receptor positive metastatic breast cancer patients.

\section{Patients and Methods}

\section{Patient eligibility}

Previously treated postmenopausal women with histologically confirmed hormone receptor positive metastatic adenocarcinoma of the breast were eligible. Hormone receptor positive disease was defined as being positive for estrogen and/or progesterone receptors by the local institutional laboratory. Patients were required to have at least one prior chemo and/or non-AI hormonal therapy for metastatic disease. Additional inclusion criteria included at least one measurable lesion by response evaluation criteria in solid tumors (RECIST), age $\geq 18$ years, Eastern Cooperative Oncology Group (ECOG) performance status of zero to two and adequate organ and marrow function (leukocytes $\geq 3000 / \mu \mathrm{l}$, absolute neutrophil count $\geq 1500 / \mu \mathrm{l}$, platelet count $\geq 100$ $000 / \mu \mathrm{l}$, total bilirubin $\leq 2.0 \mathrm{mg} / \mathrm{dl}$, aspartate aminotransferase and/or alanine aminotransferase $\leq 2.5 \times$ institutional upper limit of normal, serum creatinine $\leq 1.5 \mathrm{mg} / \mathrm{dl}$ ). Exclusion criteria included patients with no prior treatment for metastatic disease, major surgery or radiation therapy within the last 4 weeks, presence of rapidly progressive lifethreatening metastases or uncontrolled comorbidities, and any active gastrointestinal disorder that altered motility or absorption.

\section{Treatment plan}

Patients received oral letrozole $2.5 \mathrm{mg}$ once daily and fulvestrant $250 \mathrm{mg}$ in a single 5-ml intramuscular injection every month which was defined as one cycle. At each monthly visit, patients underwent a history, physical exam, complete blood count, serum creatinine, electrolytes, liver function tests, and assessment of performance status, adverse events, and drug adherence. Treatment was continued without interruption until disease progression, or intolerable toxicity. Concurrent bisphosphonate therapy with an approved bisphosphonate was permitted for patients with bone metastases.

\section{Evaluation of response and toxicity}

All patients underwent computed tomography (CT) of the chest and abdomen and a bone scan within 4 weeks of registration. Tumor response was assessed every three cycles by CT using RECIST criteria, and bone scans were repeated if the original bone scan was positive or progressive bony metastatic disease was suspected. Toxicity was graded according to the National Cancer Institute Common Terminology for Adverse Events, version 3.0. The primary end point of the study was Clinical Benefit Rate, which was defined as objective response complete response (CR) plus partial response (PR) or stable disease (SD) in the absence of any new lesions. All patients were included in the efficacy and the safety analysis. Possible predictive factors for clinical benefit rate including age (more than 65 versus younger), number of prior treatments (less than 4 versus more), hormone receptor status (ER positive/ PgR positive versus ER postive/PgR negative), histology (lobular versus non-lobular), sites of metastatic disease (bone only versus visceral with or without bone) and presence or absence of prior non-AI endocrine therapy were evaluated by using Fisher's Chi-square test.

\section{Results}

Baseline characteristics of 32 patients are shown on (Table 1). Of 32 patients, 23 met the definition for clinical benefit including 3 patients with CR, 7 patients with $\mathrm{PR}$, and 13 patients with SD, with a total clinical benefit rate of $71 \%$ (Figure 1). Nine patients progressed under therapy. Among those 23 patients who achieved clinical benefit 20 had prior non-AI endocrine therapy for metastatic disease. 16 of 23 patients who exhibited clinical benefit achieved best clinical response by 6 months and the remaining seven patients achieved their best response after 6 months. Mean duration of the clinical benefit was 15 months (range 2-38).

Age more than 65 versus younger ( $89 \%$ versus $46 \%, \mathrm{P}=0.007$ ), prior treatments less than 4 versus more ( $87 \%$ versus $25 \%, \mathrm{P}=0.0007)$ and $\mathrm{ER}+/ \mathrm{PgR}+$ versus $\mathrm{ER}+/ \mathrm{PgR}-(84 \%$ versus $42 \%, \mathrm{P}<0.05)$ were predictive of clinical benefit; lobular histology, bone only versus visceral metastases with or without bone disease, and prior non-AI endocrine therapy did not predict clinical benefit $(\mathrm{P}>0.05)$, (Table 2).

There were no grade 3-4 toxicities. The most common grades 1-2 adverse events occurring in at least $5 \%$ of patients included nausea $(5 \%)$, fatigue $(9 \%)$, anxiety $(6 \%)$, hyperglycemia (6\%), hypocalcemia $(6 \%)$, and anorexia (6\%). No patients discontinued treatments due to toxicity.

\begin{tabular}{|c|c|c|}
\hline Baseline Characteristics & $\mathrm{N}$ & $\%$ \\
\hline Patients enrolled & 32 & \\
\hline $\begin{array}{l}\text { Age at enrollment, years } \\
\text { Mean } \\
\text { Range }\end{array}$ & $\begin{array}{c}70 \\
35-92\end{array}$ & \\
\hline Race/Ethnicity & White & 100 \\
\hline $\begin{array}{l}\text { ECOG Performance Status } \\
\qquad 0 \\
1 \\
2\end{array}$ & $\begin{array}{c}2 \\
11 \\
19\end{array}$ & $\begin{array}{c}6 \\
35 \\
59\end{array}$ \\
\hline $\begin{array}{l}\text { Sites of metastatic disease } \\
\text { Bone only } \\
\text { Visceral with/without bone }\end{array}$ & $\begin{array}{l}12 \\
20\end{array}$ & $\begin{array}{l}37 \\
63\end{array}$ \\
\hline $\begin{array}{l}\text { Hormone receptor status } \\
\text { ER +/PR + } \\
\text { ER +/PR - }\end{array}$ & $\begin{array}{r}25 \\
7\end{array}$ & $\begin{array}{l}78 \\
22\end{array}$ \\
\hline $\begin{array}{l}\text { Histology } \\
\text { Lobular } \\
\text { Non-Lobular }\end{array}$ & $\begin{array}{c}8 \\
24\end{array}$ & $75 \quad 25$ \\
\hline $\begin{array}{l}\text { Prior metastatic therapy (endocrir } \\
\text { endocrine) } \\
\text { Mean } \\
\text { Range }\end{array}$ & $\begin{array}{c}2 \\
2-6\end{array}$ & \\
\hline Prior endocrine therapy (non-Al) & 25 & 78 \\
\hline
\end{tabular}

Table 1: Baseline Characteristics of Patients. 
Citation: Copur MS, Obermiller AM, Ramaekers R, Bolton M, Luebbe B, et al. (2011) Letrozole and Fulvestrant Combination in Second Line or More for Estrogen Receptor Positive Metastatic Breast Cancer; Efficacy and Predictive Factors of Response. J Cancer Sci Ther S2. doi:10.4172/1948-5956.S2-003

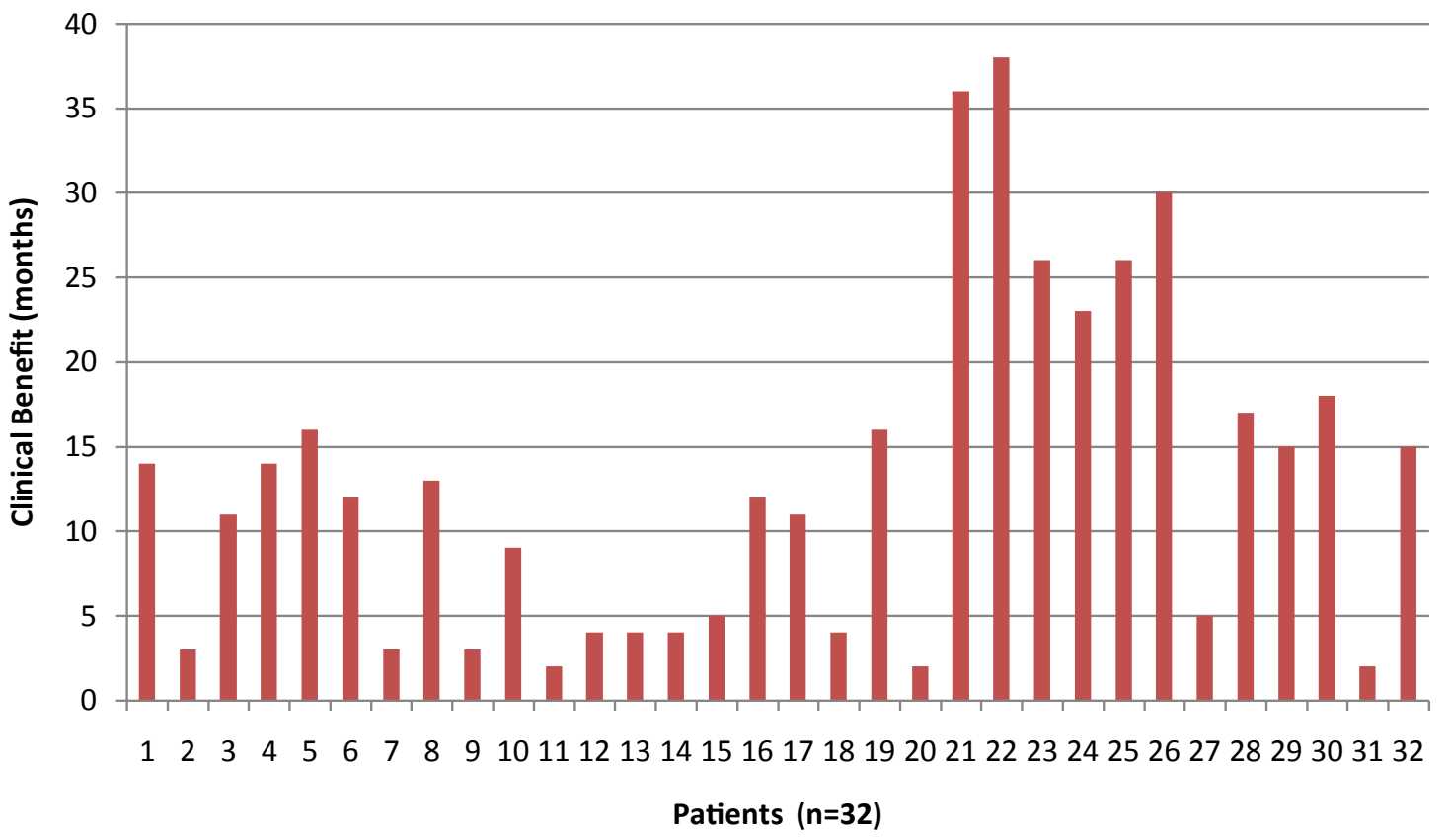

Figure 1: Clinical Benefit Rate of 32 patients while on letrozole +fulvestrant.

\section{Discussion}

While the beginnings of endocrine therapy for breast cancer, the first truly successful targeted therapy, can be traced to the 19th century, [12] the exact mechanisms of tumor response and resistance to endocrine manipulation still remain to be elucidated. Although several endocrine therapies, including selective ER modulators, aromatase inhibitors (AIs), progestins, androgens, and luteinizing hormonereleasing hormone (LHRH) agonists, and an estrogen receptor down regulator available today, the search for optimal endocrine agent, optimal combination, and optimal sequencing continues. Preclinical data have shown that complete estrogen blockade, by down regulating ER and inhibiting estrogen synthesis, has greater effect on tumor growth than either treatment alone [8,9]. Since the major source of estradiol in postmenopausal women is by aromatization of androgens, the combination of AIs with fulvestrant may enhance the efficacy of fulvestrant by reducing plasma estrogen levels. We evaluated the efficacy of combination therapy letrozole plus fulvestrant in 32 postmenopausal patients with hormone receptor positive metastatic breast cancer patients who had prior chemotherapy and/or non-AI endocrine therapy. The primary end point of our study was clinical benefit rate. We also looked for predictive factors of clinical benefit including age, number of prior treatments, hormone receptor status, histology, sites of metastatic disease, and prior non-AI endocrine therapy in this patient population. Our data show that combination of letrozole and fulvestrant can provide a meaningful and durable clinical benefit rate in this patient population. Older age, less than four prior lines of therapy, and expression of both ER/PgR are predictive of clinical benefit while lobular histology, bone versus visceral disease and prior non-AI endocrine therapy are not.

A number of ongoing or completed studies are trying to address the value of AI and Fulvestrant combination but so far no conclusive data are available. Massarweh [13] conducted a phase II trial to evaluate the efficacy of anastrozole/ fulvestrant/gefitinib as initial therapy in postmenopausal women with locally advanced or metastatic breast cancer. While the planned sample size was 60 patients, the trial was closed after 15 patients due to poor accrual. Of the 15 patients entered into the trial, 3 patients withdrew. Of the remaining 12 patients, 2 had a compete response, 5 had a partial response, 5 had stable disease, and 2 had progressive disease. Mrozek et al. [14] reported preliminary results of an ongoing phase II trial evaluating the combination of fulvestrant and exemestane in postmenopausal women with hormone receptor positive advanced breast cancer previously treated with chemotherapy, tamoxifen, or nonsteroidal AIs in the adjuvant or advanced disease setting. Patients received exemestane $25 \mathrm{mg}$ starting on day 1 , with fulvestrant $250 \mathrm{mg}$ monthly added on day 8 . At the time of the report, 19 women had been enrolled. Nine patients had a progression-free survival of more than 6 months (range: 6-20 months), with 8 of these patients still receiving treatment. An additional 8 patients had progression prior to 6 months. Accrual to this trial is ongoing.

So far the largest reported trial, FACT (Fulvestrant and Anastrozole in Combination Trial) randomized hormone receptor-positive metastatic breast cancer patients to the combination of the fulvestrant low dose regimen plus anastrozole versus anastrozole alone at the first relapse. There was no difference in time to progression and overall

\begin{tabular}{|c|c|c|}
\hline Predictive Factor & Clinical Benefit $\%$ & P value \\
\hline $\begin{array}{c}\text { Age } \\
>65 \text { versus }<65\end{array}$ & 89 versus 46 & $<0.007$ \\
\hline $\begin{array}{c}\text { Prior metastatic treatment ; } \\
<4 \text { versus }>4\end{array}$ & 87 versus 25 & $<0.0007$ \\
$\begin{array}{c}\text { Hormone receptor status } \\
\text { ER+/PR+ versus ER+/PR- }\end{array}$ & 84 versus 42 & $<0.05$ \\
\hline
\end{tabular}

Table 2: Predictive Factors of Clinical Benefit. 
Citation: Copur MS, Obermiller AM, Ramaekers R, Bolton M, Luebbe B, et al. (2011) Letrozole and Fulvestrant Combination in Second Line or More for Estrogen Receptor Positive Metastatic Breast Cancer; Efficacy and Predictive Factors of Response. J Cancer Sci Ther S2. doi:10.4172/1948-5956.S2-003

Page 4 of 4

survival [11]. Two other large phase III trials, Southwest Oncology Group (SWOG) SO226 and SOFAE (Study of Faslodex versus Exemestane with/without Arimidex), in postmenopausal women with metastatic breast cancer following progression on nonsteroidal AIs are currently ongoing. Both studies are utilizing the fulvestrant low dose regimen, $250 \mathrm{mg}$ monthly injection. SWOG-S0226 will compare anastrozole to anastrozole plus fulvestrant as first-line therapy in postmenopausal women. SoFEA study has enrolled patients who have had disease progression after an aromatase inhibitor randomizing them to fulvestrant, exemestane, or fulvestrant plus anastrozole [10]. Results of these two large trials are eagerly awaited. Finally, Di Leo et al. [15] recently showed significantly improved clinical benefit of the fulvestrant high dose regimen compared to approved dose regimen in postmenopausal women with ER-positive tumors who were previously exposed to at least one endocrine therapy. The fulvestrant high dose regimen consisted of a $500 \mathrm{mg}$ injection on day 1 , day 14 , and day 28 , followed by monthly $500 \mathrm{mg}$ injections thereafter.

Our data shows that letrozole and fulvestrant combination can be a reasonable option in a selected group of previously treated metastatic breast cancer patients. The efficacy of this combination even at low dose fulvestrant schedule is encouraging. Larger studies of this combination using high dose fulvestrant schedule is warranted.

\section{References}

1. Cole MP, Jones CT, Todd ID (1971) A new antiestsrogenic agent in late breas cancer: an early appraisal of $\mathrm{ICl} 46474$. Br J Cancer 25: 270-275.

2. Pritchard $\mathrm{KI}$ (2000) Endocri ${ }^{\mathrm{TM}}$ ne therapy for breast cancer. Oncology (Williston Park) 14: 483-492.

3. Howell A, Robertson JF, Quaresma Albano J, Aschermannova A, Mauriac L, et al. (2002) Fulvestrant, formerly ICI 182,780, is as effective as anastrozole in postmenopausal women with advanced breast cancer progressing after prior endocrine treatment. J Clin Oncol 20: 3396-3403.

4. Osborne CK, Pippen J, Jones SE, Parker LM, Ellis M, et al. (2002) Doubleblind, randomized trial comparing the efficacy and tolerability of fulvestrant versus anastrozole in postmenopausal women with advanced breast cancer progressing on prior endocrine therapy: results of a North American trial. J Clin Oncol 20: 3386-3395.
5. Howell A, Robertson JF, Abram P, Lichinitser MR, Elledge R, et al. (2004) Comparison of fulvestrant versus tamoxifen for the treatment of advanced breast cancer in postmenopausal women previously untreated with endocrine therapy: a multinational, double-blind, randomized trial. J Clin Oncol 22: 16051613.

6. Gradishar WJ, Sahmoud T (2005) Current and future perspectives on fulvestrant. Clin Breast Cancer 6: S23-S29.

7. Robertson JF, Come SE, Jones SE, Beex L, Kaufmann M, et al. (2005) Endocrine treatment options for advanced breast cancer--the role of fulvestrant Eur J Cancer 41: 346-356.

8. Macedo LF, Sabnis GJ, Goloubeva OG, Brodie A (2008) Combination of anastrosole with fulvestrant in the intratumoral aromatase xenograft model. Cancer Res 68: 3516-3522.

9. Jelovac D, Macedo L, Goloubeva OG, Handratta V, Brodie AM (2005) Additive antitumor effect of aromatase inhibitor letrozole and antiestrogen fulvestrant in a postmenapausal breast cancer model. Cancer Res 65: 5439-5444.

10. Dodwell D, Coombes G, Bliss JM, Kilburn LS, Johnston S, et al. (2008) Combining fulvestrant with continued oestregen suppression in endocrine sensitive advanced breast cancer: the SoFEA trial. Clin Oncol (R Coll Radiol) 20: $321-324$

11. Bergh J, Jonsson PE, Lidbrink E (2009) First results from FACT--An open-labe randomized phase III study investigating loading dose of fulvestrant combined with anastrozole versus anastrozole at first relapse in hormone recepto positive breast cancer [abstract 23a]. San Antonio Breast Cancer Symposium, San Antonio, TX

12. Love RR, Philips J (2002) Oophorectomy for breast cancer: history revisited. J Natl Cancer Inst 94: 1433-1434.

13. Massarweh SA, Tham YL, Weis $H$ (2007) A phase II study of anastrozole and fulvestrant in combination with gefitinib in patients with newly diagnosed ERpositive breast cancer [abstract 1050]. American Society of Clinical Oncology Meeting, Chicago, IL

14. Mrozek E, Schaaf LJ, Ramaswamy B (2008) Phase II trial of exemestane in combination with fulvestrant in postmenopausal women with hormone responsive advanced breast cancer: no evidence of a pharmacokinetic interaction between exemestane and fulvestrant [abstract 6131]. San Antonio Breast Cancer Symposium, San Antonio, TX.

15. Di Leo A, Jerusalem G, Petruzelka L, Torres R, Bondarenko IN, et al. (2010) Results of the CONFIRM phase III trial comparing fulvestrant $250 \mathrm{mg}$ with fulvestrant $500 \mathrm{mg}$ in postmenopausal women with estrogen receptor-positive advanced breast cancer. J Clin Oncol 28: 4594-4600. 